\title{
Some Differences between Maturana and Varela's Theory of Cognition and Constructivism
}

\author{
JÉRÔME PROULX \\ University of Ottawa (Canada)
}

\begin{abstract}
The theory of cognition of Varela and Maturana differs in specific aspects from constructivist theories and so should not be seen or interpreted as another form of constructivism. To encourage the emergence of a discussion on important differences between both theories, this paper aims at highlighting three of these specific aspects, namely the biological roots of cognition, its phylogenic and ontogenic basis, and the nature of reality and knowledge. In many regards, it is possible that the first two points were seen as extensions of constructivism, and had not been theorized previously as distinctions, as is done in the paper. The third point concerning the ideas of "bringing forth a world" represents a clear conceptual shift from the visions inherent in constructivism, and should not be neglected in discussions on epistemology and the nature of knowledge and reality. This third fundamental point brings us to see Varela and Maturana as being different than constructivists, rather seeing them as "bring forthists."
\end{abstract}




\section{Introduction}

Whereas the twentieth century was seen as the century of physics, the twenty-first is often predicted to be the century of biology. (Barabasi 2003, p. 197)

The cutting-edge work on cognition of Humberto Maturana and Francisco Varela has had an important influence on those interested in aspects of complexity theory and education, particularly in regard to issues and questions of epistemology, learning, knowledge, objectivity, causality, self-organisation, emergence, ethics, and so on. Their position on knowledge as not being pre-existent or as "taking things in" and rather as being enacted and emerging through the learner's engagement with his world is at the core of the complexivist discourse on learning, knowledge and education. Notably, with this position on knowledge, they define the knower as a complex agent that is selforganizing, self-maintaining and structurally determined, meaning that, as Davis (2004a) explained, "the way that a complex system responds to a situation is determined by the system itself, not the situation."

However, Maturana and Varela's ground-breaking theory of cognition, often termed "enactive" or "enactivism" (e.g., Davis, 2004b) or the "Santiago theory of cognition" (e.g., Capra, 1996) ${ }^{1}$, is often conflated with diverse forms of constructivism (e.g., Riegler, 2005). Having been educated in the constructivist "tradition" in my masters' studies, my doctoral studies acquainted me with the theory of cognition pioneered by Maturana and Varela (e.g., Maturana \& Varela 1992). To my understanding, there are some important differences between the two, differences that are worth acknowledging and this is the intention grounding this theoretical paper. I do this to encourage discussion of what I see as three important differences between Maturana and Varela's position and the constructivist one.

The use of "differences" is maybe too strong of a word here to discuss both theories, since the first two points that I will highlight - the phylogenic/ontogenic nature of knowledge and the biological base of cognition - are not contrary to or in disagreement with constructivism but should mostly be seen as an extension of its roots. These two first points, though, still create a subtle but important distinction. The third point however, concerning the idea of "bringing forth a world," appears to be an important conceptual break from constructivism - one with which I believe some constructivists would disagree. It is indeed along that point that Varela (1996) implied that his theory diverged from any form of constructivism, something Tomm (1989) also mentioned concerning Maturana's views.

This paper is structured in three parts. The first part elaborates on some key aspects of constructivism (namely, knowledge, subjectivity and viability) and of Maturana and Varela's theory of cognition (namely, structural coupling and structural determinism) in

\footnotetext{
${ }^{1}$ To my knowledge, only Varela used and referred to the expression "enaction" or "enactive," whereas Maturana talked more in terms of "bringing forth a world" and of "objectivity in parenthesis." Hence, to clarify the discussion and avoid confusion, I use the expression "Maturana and Varela's theory of cognition" throughout the article.
} 
order to ground the subsequent arguments about both discourses. These are used to situate and ground the subsequent arguments. The second part concerns the biological traits of the theory that makes it a "biological theory of cognition" and not simply a theory of "human cognition." In that section, notions of biological cognition as adequate conduct (Maturana, 1987) and of the roots of knowledge in terms of phylogeny and ontogeny frame the discussion. The third part concentrates on the "nature" of knowledge or the process of coming to know, representing the major conceptual distinction between both theories. This is elaborated in line with notions of "world of experience," "physical world" and "bringing forth a world of meaning" - in other words, of epistemological questions of reality. Building on this, I demonstrate how Maturana and Varela's theory departs from the dichotomy between subject and object and develops something that could be referred to as objectivity in parentheses (Maturana, 1988; Maturana \& Poerksen, 2004) or interobjectivity (Latour, 1996), which encompasses ideas of objectivity, subjectivity and intersubjectivity ${ }^{2}$.

\section{Introducing some key concepts of constructivism and of Maturana and Varela's theory of cognition}

In referring to constructivism, I mostly refer to Piaget and Glasersfeld's writings. The reason is simple: Glasersfeld is the author who has promoted (and extended) extensively Piaget's theory in education and therefore represents a fundamental author concerning constructivism in education. There are of course many forms of constructivism and it would be a mistake to conflate all of them into a single perspective. The first two points/distinctions that I outline in this paper appeal to most constructivist discourses (individual, social, etc. - see Geelan, 1997, Larochelle, Bednarz, \& Garrison, 1998, or Phillips, 1995, for an overview of many forms of constructivism in the educational literature). However, the third distinction made concerning epistemology mainly refers to Glasersfeld's radical constructivism since aspects of epistemology represent a fundamental aspect in his constructivism (and Piaget's also). Because of space constraints I am not able to go in lengths about all aspects of the theory, but I offer here a summary of some important points, which enables a grounding of the discussions and arguments presented afterwards, as other points are clarified throughout the rest of the paper ${ }^{3}$.

One of the first things to say is that for constructivists, learning is seen as an active process, and not as a passive one. It is not a matter of linearly acquiring and accumulating knowledge, but of actively construing and modifying our own

\footnotetext{
${ }^{2}$ It is not my intention in this paper to summarize Maturana and Varela's work or show its similarities with constructivist theories. In that sense, I am well aware that my report on their theory is incomplete. To grasp the overarching frame and similarities, I refer the reader to the following selected pieces of the seminal work: Maturana 1987; Maturana 1988; Maturana and Varela 1992; Varela 1987; Varela 1996; Varela 1999; Varela, Thompson and Rosch 1991.

${ }^{3}$ For a more extensive elaboration or a clarification of aspects of constructivism, I refer the reader to an article I have published elsewhere (Proulx, 2006).
} 
"knowings." As for knowledge, whereas socio-constructivists would define it as an inherently social endeavour, radical constructivists assert that knowledge is an individual, personal construal that is shaped by our own experiences as learners in this world:

What is radical constructivism? It is an unconventional approach to the problem of knowledge and knowing. It starts from the assumption that knowledge, no matter how it is defined, is in the heads of the persons, and that the thinking subject has no alternative but to construct what he or she knows on the basis of his or her experience. (Glasersfeld, 1995, p. 1)

This idea of considering knowledge as a personal construct is not new in itself. Rationalists and empiricists in the 17th century asserted that individuals constructed their own understandings (Davis, 2004b). The important shift here with constructivism is that learning and personal knowledge are not seen in terms of an internal construction or a representation of an external world - as Descartes, Locke and other rationalempiricists asserted. Whereas rationalists and empiricists assert that they are able to obtain and prove a universal reality, a universal truth that would be independent of the learner, an objective reality, constructivism claims that we have no access to an objective truth and that all knowledge is subjective and dependent on the learner.

Constructivism ideas goes back to Vico, who considered human knowledge a human construction that was to be evaluated according to its coherence and its fit with the world of human experience, and not as a representation of God's world as it might be beyond the interface of human experience. Constructivism drops the requirement that knowledge be 'true' in the sense that it should match an objective reality. (Glasersfeld, 1992, p. 3)

Hence, instead of talking about an internal representation that reflects the external world, constructivism describes personal knowing in terms of fitting to, and compatibility with, the experiential world. The theories of knowledge articulated by rationalists and empiricists have been dubbed 'correspondence theories' because of their assumption that the accuracy of personal knowledge has to do with its match to objective reality. The idea of 'matching' implies a direct relation between two objects - a mapping one to one, a correspondence. In other words, the two objects can be considered exactly the same. This is what is intended in the idea of constructing an internal representation of an external world, or the familiar metaphor of personal knowledge as a continuously refined mirror of reality. In opposition, the constructivist idea of 'fitting' is speaking in terms of viability and compatibility in relation to the experiential world we live in.

Simply put, the notion of viability means that an action, operation, conceptual structure, or even a theory, is considered "viable" as long as it is useful in accomplishing a task or in achieving a goal that one has set for oneself. (Glasersfeld, 1998, p. 24)

Meanings construed by individuals are subjective knowledge in the sense that it is through their own interpretations of their experiences that they came to know. Knowledge is affected by the learner's own subjective vision of things, as the 
experiences of the learner act as a filter through which all future experiences will be interpreted and understood:

[...] we have no way of checking the truth of our knowledge with the world presumed

to be lying beyond our experiential interface, because to do this, we would need an access to such a world that does not involve our experiencing it. (Glasersfeld, 1990, p. 20, my emphasis)

Therefore, epistemologically speaking, one could say that Glasersfeld replaces the notion of 'objective and ontological truth' with that of viability; the key for constructivists is an adequate fit, not an optimal match.

Now that some grounding principles of constructivism have been laid out (and other will be in following sections through the arguments), let's turn to aspects of Maturana and Varela's biological theory of cognition.

Maturana and Varela offer a biological theory of cognition, which means that human knowledge and meaning making processes are understood and theorized from a biological and evolutionary standpoint. In other words, for Maturana and Varela, our biology matters in the process of coming to know. Important in this theory, and specifically relevant for the argument here, is the concept of natural drift, a concept that has its roots in Charles Darwin's theory of evolution, and that centers on two specific notions, that is structural coupling and structural determinism.

To make sense of the process of survival of species, Darwin used the concept of "fitting," which is also a concept that constructivism heavily refers to explain issues of viability (e.g., Glasersfeld, 1989). For species to survive, it must continuously adapt to its environment, to fit within it. If not, it would perish. In a sense, Darwin offered a pejorative or negative view of the survival of species: species that survived just simply did not die - and continued to adapt. The concept of fitting is, however, not a static one in which the environment stayed the same and only the species evolved and continued to adapt. Darwin explained that species and environment co-evolve, Maturana and Varela (1992) add that they co-adapt to each other, meaning that each influences the other in the course of evolution ${ }^{4}$. In other words, the fit was an evolving one, with both parties evolving5. The idea of co-evolution between environment and species is key in regard to the origin of the changes or adaptations of the species to its environment. By co-evolving, species and environment experience a history together and influence each other in this process. This is why it sometimes seems as if some species are so

\footnotetext{
${ }^{4}$ The concept of natural drift, as one of the reviewers accurately outlined, can be perceived to offer a critique to the adaptationist view of evolution that is said to unfold from Darwin's theory. For instance, Varela et al. (1991) call natural drift "an alternative view of evolution" (p. 201). However, as Varela (1984, p. 201) explains, this critique is addressed not to Darwin's theory of evolution, but to the adaptationist programme which for Varela appears to be quite divergent from the original Darwinian theory of evolution, as it misleadingly focuses on "optimal fitness" or "survival of the fittest," instead of simply the "survival of the fit" as Darwin expressed. This represents in fact an issue that Darwin himself often mentioned in his writings as one of the main misinterpretations of his work (see Howard, 2001). Maturana and Varela (1992) also offer another critique of the misinterpretations of Darwin's theory from his successors, mainly in relation to the expression "natural selection."

${ }^{5}$ Capra (1996) explains that this creates a shift from evolution to co-evolution.
} 
compatible with their environment that they appear to be "perfectly made for it," and, inversely, that the environment seems perfectly suited for the species 6 .

This notion is called structural coupling by Maturana and Varela, in the sense that both environment and organism interact with one another and experience a mutual history of evolutionary changes and transformations. Both organisms and environment undergo changes in their structure in the process of evolution and this makes them "adapted" and compatible with each other.

Every ontogeny occurs within an environment $[\ldots]$ it will become clear to us that the interactions (as long as they are recurrent) between [organism] and environment will consist of reciprocal perturbations. [...] The results will be a history of mutual congruent structural changes as long as the [organism] and its containing environment do not disintegrate: there will be a structural coupling. (p. 75, emphasis in the original)

Here, the environment does not act as a selector, but mainly as a "trigger" for the species to evolve - as much as species act as "triggers" for the environment to evolve. Maturana and Varela explain that events and changes are occasioned by the environment, but they are determined by the species structure.

Therefore, we have used the expression "to trigger" an effect. In this way we refer to the fact that the changes that result from the interaction between the living being and its environment are brought about by the disturbing agent but determined by the structure of the disturbed system. The same holds true for the environment: the living being is a source of perturbations and not of instructions. (p. 96, emphasis in the original)

Maturana and Varela call this phenomenon structural determinism, meaning that it is the structure of the organism that allows for changes to occur, changes "triggered" by the interaction of the organism with its environment. They give the following example: A car that hits a tree will be destroyed, whereas the same thing would not happen to an army tank. And so, the changes do not reside inside of the "trigger" (inside the tree); they come from the organism interacting with the "trigger." The "triggers" from the environment are essential, but they simply do not determine the changes. In short, changes in the organism are dependent on, but not determined by, the environment. With this, structural coupling can be redefined in terms of the history of co-evolution and co-influence of species and environment, determined by each parties' structure ${ }^{7}$.

\footnotetext{
6 A striking example of that appeared in Science et Vie (June 2005) where it discusses a strategic association between ants and a plant to capture, for example, grasshoppers, where the plant offers a site for ants to live in where ants puncture holes in the plant branches in order to hide and capture any insect that walks on the plant in order to eat its leaves. The ants capture the insect and feed themselves from it. Both living organisms gain from this association where the plant, through offering the ants to live and feed themselves from the insect that attempt to eat her leaves, receives in return a protection against the herbivore insects attracted by its leaves.

${ }^{7}$ Maturana and Varela explain, it is important to notice, that for a specific species all other species are part of the external "environment" and do not have a specific/different status than anything else that is external to it - even if they can be conceptualized as having different attributes on some levels.
} 


\section{Cognition as a biological act}

\section{Human knowledge vs biological knowledge}

For Maturana and Varela, the structural changes that an organism undergoes when it structurally couples with its environment are seen as acts of cognition, in the sense that they are adaptive responses to the environment. It is these adaptive responses to the environment, these interactions, that form the process of life itself. In that sense, for Maturana and Varela, "to live is to know" (p. 174). Along that line, knowledge is defined as an adaptive response, as adequate conduct (Maturana, 1987) or effective action (Maturana \& Varela, 1992), which is well summarized by their maxim, "All doing is knowing and all knowing is doing" (Maturana \& Varela 1992, p. 27).

When cognition is seen as the process of living itself, it does not necessarily need a human brain, or even a brain. It is the "evolutionary" concept of structural coupling with the environment and of continuing to being adapted to it (within the structural changes) that defines a living system's cognition. In that sense, all animals, plants, bacteria - all living systems - are cognitive. As Capra (1996) explains:

Even bacteria perceive certain characteristics of their environment. They sense chemical differences in their surroundings and, accordingly, swim toward sugar and away from acid; they sense and avoid heat, move away from light or toward it, and some bacteria can even detect magnetic fields. (p. 268)

Defined in these terms, cognition encompasses more than human knowledge, and takes into account all living systems. This has indeed been highlighted (cf., Davis, Sumara \& Luce-Kapler 2000, chap. 2A; Davis 2004b, chap. 10) as one distinction between biologically based discourses (e.g., enactivism, ecology, complexity) and intersubjectivist discourses (e.g., constructivism, socio-constructivism, cultural and critical discourses).

In addition, there is a different usage and definition of structure here in regard to Maturana and Varela's work and that of constructivism. In line with Piaget's writings, constructivists discuss issues of structure in terms of coherence and viability of the knowledge construction and experiences lived. The meaning assigned and construed from an experience fits within previous coherences and understandings. It is then a metaphorical use of "structure" in the sense of thoughts and knowledge base. Because they define knowledge in terms of adequate action, Maturana and Varela's use of structure is literal, in the sense of an organism's own biological structure with which it adapts to its environment. And it is with this biological structure that the organism makes sense of the world and displays "adequate conduct." The usage of structure is obviously again linked to knowledge, but in a literal manner, not in a metaphorical one

Therefore, even if it is indeed true that constructivism has strong bases in Piaget's writings - noting that he was a biologist himself - and that the concept of "fitting" has roots in Darwin's ideas and is cited frequently by Glasersfeld (e.g., 1984, 1989, 1990), constructivist discourses focus specifically on human knowledge and do not encompass animals, plants, and so on. This "situatedness" of cognition within biology, which makes it a characteristic of all living beings, creates a significant point of distinction. This point 
is not necessarily a site of disagreement between constructivism and Maturana and Varela's theory of cognition, but is still an important one of differentiation.

\section{Phylogeny and ontogeny}

Constructivism, with its use of Piaget's concepts of adaptation of knowledge theorized within accommodation and assimilation processes and its use of the previously mentioned notion of "fit," brings rich insights into the process of experiential learning. It could even be said that constructivism is interested in describing our ontogeny, that is, our learned lived experience or individual development ${ }^{8}$.

However, constructivism does not take into account, or simply does not theorize about, innate knowledge, that is, the idea that humans are born with certain capacities (for example, the capacity to discern objects, sounds, or other sensory events). The presence of innate knowledge is even rejected by many or is considered a taboo that should not be discussed. This is indeed part of the longstanding debate or dilemma between nature and nurture.

Despite the taboo, studies in cognitive science have extensively shown that humans (and even animals) possess some innate knowledge or capacities at birth. For example, it has been shown that newborns can subitize ${ }^{9}$ and do simple addition and subtraction operations (see Lakoff and Nùñez 2000, chap. 1, for a summary of some of these results in cognitive science). This obviously brings a new perspective on our understanding of knowledge and learning.

By situating cognition at a biological level, Maturana and Varela consider living beings within their species' lineage, that is, each species possesses a phylogeny that defines it as a species. A species' phylogeny is its history of changes in its evolutionary development and diversification. For humans, this phylogeny is what distinguishes and defines us as a distinct species (and other species distinguish themselves from us by theirs). It describes us, defines us and even predisposes us to be human. Through the successive evolutionary changes, the human species evolved to become what it is now (see Capra 1996, chap. 10, for a summary of life and the human species lineage). As Prigogine puts it, human beings "carry their history on their back" (in Juarrero 2002, p. 140).

In a sense, our phylogeny is the structure with which we start as humans. We are, as individuals within this biological lineage, predisposed to be humans physically and intellectually: we possess all there is needed at the moment that we are born. Donald

\footnotetext{
${ }^{8}$ Biologically, however, ontogeny is often seen as beginning with the fertilization of the egg. Maturana and Varela (1992) define it as "the history of structural change in a unity without loss of organization in that unity. This ongoing structural change occurs in the unity from moment to moment, either as a change triggered by interactions coming from the environment in which it exists or as a result of its internal dynamics." (p. 74)

${ }^{9}$ To "subitize" means to be able to instantly discern or distinguish at a glance whether there are one, two or three objects in front of you.
} 
(2001) talks metaphorically about the intellectual predisposition as a "tool box" ready to be used ${ }^{10}$.

However, our biological inheritance, our phylogeny, is much more than our innate "tools." There is also some inherited knowledge (from the species), which we could call the instinctive behaviours or the innate capacities. Some knowledge has been developed by our species itself within its evolution and these are transmitted to us by our phylogeny. These are biological knowledge or behaviours that we have when we are born: opening our eyes or closing them, locating the maternal breast, and so on. At the biological level, much knowledge is transmitted without our having to "learn" from ontogenic experience; our species has learnt it for us. Moreover, contemporary research in cognitive science is extending and complexifying understandings of the type of innate knowledge we possess at birth - our innate arithmetic capacities being a good example ${ }^{11}$.

In this sense, Maturana and Varela's theory takes into account both phylogeny and ontogeny. "So not only are we here now as a result of our personal histories, but we are here now as a result of the history of our ancestors" (Maturana 1987, p. 78). Both are knitted into our individual knowledge base and play fundamental roles in our development. However, they are also very difficult to distinguish, as Maturana and Varela (1992) explain:

Note well that innate behavior and learned behavior are, as behaviors, indistinguishable in their nature and in their embodiment. The distinction lies in the history of the structures that make them possible. Therefore, our classifying them as one or the other depends on whether or not we have access to the pertinent structural history. We cannot make that distinction by observing the operation of the nervous system in the present. (pp. 171-172)

Again, it is the biological "situatedness" of Maturana and Varela's theory of cognition that enables it to take into account these aspects. This is not necessarily contradictory to constructivism, but it does create a distinction from it because constructivism does not attempt to theorize or make sense of phylogeny. Hence, it appears important to consider it for Maturana and Varela.

Now that some aspects concerning biology and issues of knowledge have been made, I turn to a third distinction that will complement these first two; one concerning issues of reality and the nature of this knowledge in relation to the merging of subject and object. To my understanding, this third distinction represents a significant conceptual break between Maturana and Varela's theory of cognition and constructivism.

\footnotetext{
${ }^{10}$ Donald (2001) explains that physically "everything is ready" to get going. We have the physical predisposition to learn. We have the "tool" to learn in the same way that we have a pencil to write. Words and messages are not already there in the pencil, but the pencil is our tool permitting us to write.

${ }^{11}$ And this body of innate knowledge is probably not static, since as we continue evolving as a species we continue learning at the biological level, maybe acquiring and developing knowledge that the first Homo sapiens did not have.
} 


\section{Maturana and Varela's theory of cognition as an interobjectivist discourse}

Positivists and realists have asserted the presence of an external truth - some thing "out there" - where learning is conceptualized as a matter of making objective sense, of representing, and of internalizing this knowledge base (Vacher, 1998; see also Fourez, Engelbert \& Mathy, 1997, for a critique of this position). Constructivism, and specifically Glasersfeld's radical constructivism, has critiqued this conception by explaining that the knower has a fundamental role in the learning process and the knowledge created. Indeed, constructivists assert that the learner, in any situation, produces knowledge and make sense of situations lived on the basis of what he or she knows, that is, on the basis of his or her previous knowledge. This points to the fact that knowledge construed by the knower is not absolute, independent or value-free, but that it is influenced/dependent of the knower who produces it (Lincoln \& Guba 1985, chap. 7), and therefore knowledge does not exist anywhere else than in the subjective experience of the knower. Hence, for Glasersfeld, as knowers, the only thing we have access to is our world of experiences. Our knowledge is then subjectively framed and can only be compatible or viable in regards to the experiential world we live in, since it is the only thing we have access to.

Radical constructivism is an attempt to develop a theory of knowing that is not made illusory from the outset by the traditional assumption that the cognizing activity should lead to a "true" representation of a world that exists in itself and by itself independently of the cognizing agent. Instead, radical constructivism assumes that the cognizing activity is instrumental and neither does nor can concern anything but the experiential world of the knower. This experiential world is constituted and structured by the knower's own ways and means of perceiving and conceiving, and in this elementary sense it is always and irrevocably subjective. (Glasersfeld, 1992, pp. 1-2)

In constructivism, the presence of an external reality is something deemed inaccessible, if it was to exist. [As previously mentioned, these issues about epistemology mainly concern Glasersfeld's radical constructivism.] Constructivism opts for the agnostic argument, saying that there maybe or there may not be an external true reality or a "book of God" - they do not know and it is impossible to know if it exists. "Therefore I limit myself to saying that I do not deny it [an external reality]. Not denying does not imply existence, it is simply part of agnosticism" (Glasersfeld website, April 2003). All I have access to is my experiential world and so anything that "exists" is in the domain of my experiences - the word "existence" has a different meaning for constructivists than for realists or positivists; for the last two, it means to exist independently of the knower. If there really is a "book of God," at the moment that I would start to read it, I would be in the domain of my experiences - I cannot detach myself from my experiences. In that sense, knowledge cannot and need not to be "true," it only has to fit, cohere and work within experiences lived. Knowledge is then subjectively or intersubjectively (where there are mutually compatible agreements arrived at) theorized.

Maturana and Varela theorize the nature of knowledge in slightly different terms. They do not assert that there is a "truth" out there waiting to be grasped or discovered - 
like realists and positivists do. However, neither do they assert that the only thing we have access to is our world of experience in an agnostic perspective - as constructivists do. Using the notions of co-evolution within structural coupling and structural determinism, Maturana and Varela's theory does away with this dichotomy of objectivity and subjectivity and explains that the knower and the known - the subjective individual and the external constraints of the learning experience - us and the physical external environment, are reciprocal and simultaneous specifications of the other. They co-define each other.

C'est le processus continu de la vie qui a modelé notre monde par ces aller et retour entre ce que nous appelons, depuis notre perspective perceptuelle, les contraintes extérieures et l'activité générée intérieurement. [It is the continuous process of life that has modeled our world by its back and forth between what we call, from our perceptual perspective, the external constraints and the internally generated activity.] (Varela, 1996, pp. 104-105)

This is in line with the work on perception of Merleau-Ponty (1962; Matthews 2002). For Merleau-Ponty, perception is an active participation, an engagement in the world, and not a separation from it. For him, we are not looking at the world from a vantage point and objectively representing that world, neither are we only subjective perceivers - we inhabit that physical world and it is by our participation in it that we bring forth this world of meanings.

To have "being-in-the-world" in this sense is neither to be a mere object, passively suffering the influence of other objects, nor to be in the God-like situation of creating the world from a position that transcends it; it is to be part of a two-way interaction between ourselves and the rest of the world out of which a meaningful structure to the world emerges. (Matthews 2002, p. 54)

Put bluntly, I need a physical world to make sense of it, and I need a structure to perceive that physical world, which allows the physical world to be perceived by myself. Without a physical world or a subjective knower, there is no meaning that can emerge. The world of meaning is not in us, nor in the physical world, it is in the interaction of both in a mutually affective relationship.

With my structure I make sense and give meaning to that physical world and bring forth a world of significance. It is a world of significance that is enabled by my structure, and also by the environment that I interact with. It is my structure that allows me to "see" or perceive things in the physical world, and so my structure allows me to give meaning to the attributes ${ }^{12}$ of the physical world. I - my structure - allow the physical world to be brought forth. If these attributes of the physical world are outside of my structure, outside of my capacity to make sense of them, I cannot distinguish them and cannot perceive them. In other words, they cannot "trigger" anything in me. Hence, I bring forth the physical world's attributes when I give/create meaning to it - I acknowledge their physical "presence" by bringing them forth. If I do not bring them

\footnotetext{
${ }^{12}$ Attributes or properties are in the sense of physical characteristics, and should not be equated with "meanings" already present, as realists or idealists would assert. It is from the interaction with the physical properties that we associate meaning to them.
} 
forth, the physical world's attributes will still be "there," but they will remain unnoticed, not made sense of and kept "in the dark." It is in this sense that the physical attributes themselves are brought forth by my interaction with them (if I perceive them). In some sense, I make the physical world emerge. But,

Maturana and Varela do not maintain that there is a void out there, out of which we create matter. There is a material world, but it does not have any predetermined features. The authors of the Santiago theory do not assert that "nothing exists"; they assert that "no things exist" independent of the process of cognition. (Capra, 1996, p. 271)

As I interact with this physical world, I bring forth a world of meaning in which a physical world is brought forth and so is myself, my structure. As I bring forth a world, I emerge with it in the sense that I am within my descriptions. It is my structure that allowed me to bring them forth.

What is brought forth by a particular organism in the process of living is not the world but $a$ world, one that is always dependent upon the organism's structure (Capra, 1996, p. 270 , emphasis in the original)

In a way, we are in the reality we bring forth. We do not bring forth any reality, we bring forth the one that we can, and so it is always dependent on us. As Maturana (1987) says, "everything is said by an observer." There are no observerless observations or knowerless knowledge. So, as I bring forth a world, I myself is brought forth within my descriptions, I am (in) my descriptions. Both knower and known are part of the world of significance brought forth.

It is within this circularity, of bringing forth and of being brought forth, that knower and known co-determine and mutually influence each other. My descriptions are altered by my structure - my capacity of describing - but are also rendered possible and altered by the "presence" of the object or phenomenon itself. And these descriptions that I make change my ways of describing (I learn), and so it changes my structure - which changes my (new) descriptions that I can make. What I describe is altered by my structure, but alters back my structure and ways of describing it. In other (circular) terms, what I describe influences my descriptions of things and my descriptions of things influence the things I describe. It is a continuous circular process where both knower and known are brought forth and co-specify each other. It is in that sense that it is the middle path between objectivity and subjectivity, that is, where the distinction between objects and subjects collapses because both are co-determinations of one and the other.

Si nous devons au contraire conclure que la cognition ne peut-être adéquatement comprise sans le sens commun, qui n'est rien d'autre que notre histoire physique et sociale, il nous faut en déduire que celui qui sait et ce qui est su, le sujet et l'objet, sont la spécification réciproque et simultanée l'un de l'autre. En termes philosophiques: le savoir est ontologique. [If we on the contrary conclude that cognition cannot be adequately understood without common sense, which is nothing else than our physical and social history, we have to deduce that the knower and the known, the subject and the object, are the reciprocal and simultaneous specification of each other. In philosophical terms: knowledge is ontological.] (Varela, 1996, p. 99, emphasis in the original) 
The word "ontological" is used metaphorically here, but it is used to flag that knowledge, the world of meaning, is not "out there" independent and outside of us, nor only within us as subjective. Knowledge is in the space of emergence where knower and known meet and co-influence each other. Knowledge or the world of meaning, then, is permeated by the knower and the known, which is also completely permeated by their history of coupling and interactions. Knowledge is ever-evolving and changing, and emerges in the continual flow of emerging interactions between knower and known. In other words, the ontology of knowledge is evolving and constantly emerges and reemerges - this is why ontology is used as a metaphor and is not used in metaphysical terms.

Additionally, these discussions undoubtedly lead us to questions about the physical world and our influence on it. As Capra (1996) said, it is not a question of creating matter. However, there is an influence on the physical world per se as I bring it forth or simply as I make sense of it. But this co-influence of knower and known should not be read literally in regard to an immediate or direct causal "effect" on the physical world. It is not because I perceive something that I physically change it, but by perceiving or making sense of something, my own actions are modified and influenced by these (new) perceptions and understandings. Hence, as I change, my actions change, and this affects on some level the physical world we inhabit: our actions change the world. This entire idea is summarized by Davis (2004b):

As our actions shift, the physical texture of the world is affected - a point that has been dramatically demonstrated over the past century. For example, the climates that we study today, the illnesses that are currently of greatest concern, and the social issues that occupy our imagination are emergent and, in obvious ways, prompted by previous habits of observation, interpretation, and action. (p. 102)

In other words, as my perceptions and understandings change me, I change my actions in the world, and the world changes. This is why Davis calls this a "participatory approach," since our participation is affected by and affects back the world we live in. The physical world itself is evolving and changing and we ourselves evolve in relation to that physical world (as it evolves).

Maturana and Varela's theory of cognition is then not within a subjective or intersubjective discourse, nor within an objective discourse: it is an interobjective discourse - Maturana also calls this objectivity in parentheses (e.g., Maturana 1988; Maturana \& Poerksen 2004). It is not that intersubjective agreements are arrived at and that these create a world, nor that I create my own subjective world, nor that there is a meaning to the physical world lying "out there." Interobjectivity asserts that it is within the junction of the physical world and I that the world of meaning emerges, it is in this continual back-and-forth influence of knower and known - in this structural coupling.

It is within this middle path, this interobjective path, that Maturana and Varela's theory distinguishes itself from the agnostic idea of reality, by making knowledge ontological and brought forth. This ontology, this bringing forth of a reality, is precisely what brings Tomm (1989) to say that: "Maturana is not a constructivist, he is a 'bring forthist'." 


\section{Conclusion}

In this paper, I have tried to underscore what I have experienced and think are three aspects that distinguish the theory of cognition of Maturana and Varela from constructivism. As I have tried to highlight, the first two distinctions concerning the biological bases of this theory of cognition are not necessarily in contradiction with constructivists' bases, but represent a possible "extension" of them: from human knowledge to biological knowledge, and from a sole focus on ontogeny and toward a focus on ontogeny and phylogeny.

However, the third element concerning the nature of reality and knowledge represents in my sense an important conceptual shift that should not be neglected. The elimination of the dichotomy between subject and object, this emphasis on codetermination and on bringing forth a world of meaning, is precisely what "démarque le point de vue de l'enaction de toute forme de constructivisme [dissociates the enactive stand point from any form of constructivism]" (Varela, 1996, p. 105), and which brought Tomm to say that Maturana is not a constructivist.

It was my intention to elaborate on some aspects where Maturana and Varela's theory diverged from constructivism, even if they do share many common cybernetic roots, to show that it should not be (mis-)interpreted as another form of constructivism. The intention was, however, not to sort out which is better and which is not, but mostly to prompt and encourage discussions and reactions around the differences (and even similarities) between both theories - to understand what makes each theory its own, and to make better sense of them. I hope to have succeeded in this and played the role of a "trigger" in that sense.

\section{References}

Barabasi, A.-L. (2003). Linked: How everything is connected to everything else and what it means for business, science, and everyday life. New York, NY: Penguin Group

Capra, F. (1996). The web of life: A new understanding of living systems. New York: Anchor Books.

Davis, B. (2004a, Oct.). Teaching with difference: Dissipating structure (Interactive panel with W. Doll \& D. Osberg). Paper presented at the 2nd annual meeting of the Complexity Science and Educational Research Conference. Kingston, Ontario, Canada.

Davis, B. (2004b). Inventions of teaching: A genealogy. Mahwah, NJ: Lawrence Erlbaum.

Davis, B., Sumara, D. \& Luce-Kapler, R. (2000). Engaging minds: Learning and teaching in a complex world. Mahwah, NJ: Lawrence Erlbaum.

Donald, M. (2001). A mind so rare: The evolution of human consciousness. New York: W.W. Norton.

Fourez, G., Engelbert-Lecomte, V. \& Mathy, P. (1997). Nos savoirs sur nos savoirs: Un lexique d'épistémologie pour l'enseignement. Brussels: De Boeck Université.

Geelan, D. R. (1997). Epistemological anarchy and the many forms of constructivism. Science and Education, 6, 15-28.

Glasersfeld, E. von (1984). An introduction to radical constructivism. In P. Watzlawick (Ed.). The invented reality: How do we know what we believe we know? Contributions to constructivism (pp. 17-40). New York: W.W. Norton.

Glasersfeld, E. von (1989). Cognition, construction of knowledge, and teaching. Synthèse, 80(1), 121140. 
JÉRÔME PROULX

Glasersfeld, E. von (1990). An exposition of constructivism: Why some like it radical? In R. B. Davis., C. Maher., \& N. Noddings (Eds.). Constructivism views on the teaching and learning of mathematics (pp. 19-29). Reston, VA: NCTM.

Glasersfeld, E. von (1992). Aspects of radical constructivism and its educational recommandations. Paper presented at ICME-7, WG\#4, Quebec, Canada. http://www.umass.edu/srri/vonGlasersfeld/onlinePapers/html/195.html

Glasersfeld, E. von. (1995). Radical Constructivism: A Way of Knowing and Learning. London and Washington: Falmer Press.

Glasersfeld, E. von. (1998). Why constructivism must be radical. In M. Larochelle., N. Bednarz., \& J. Garrison (Eds.). Constructivism and Education (pp. 23-28). Cambridge University Press: Cambridge.

Glasersfeld, E. von, website. http://www.oikos.org/vonen.htm\#QUESTIONS (visited July 23rd, 2007).

Howard, J. (2001). Darwin: A very short introduction. Oxford: Oxford University Press.

Juarrero, A. (2002). Dynamics in action: Intentional behavior as a complex system. Cambridge, MA: MIT Press.

Lakoff, G. \& Núñez, R.E. (2000). Where mathematics comes from: How the embodied mind brings mathematics into being. New York: Basic Books.

Larochelle, M., Bednarz, N., \& Garrison, J. (Eds.). (1998). Constructivism and education. Cambridge: Cambridge University Press.

Latour, B. (1996). On interobjectivity. Mind, culture, and activity, 3(4), 228-245.

Lincoln, Y.S. \& Guba, E.G. (1985). Naturalistic inquiry. Newbury, CA: Sage Publications.

Matthews, E. (2002). The philosophy of Merleau-Ponty. Montreal and Kingston: McGill-Queen's University Press.

Maturana, H.R. (1987). Everything is said by an observer. In W.I. Thompson (Ed.). Gaia: A way of knowing. Political implications of the new biology (pp. 65-82). New York: Lindisfarne Press.

Maturana, H.R. (1988). Reality: The quest for objectivity or the quest for a compelling argument. The Irish Journal of Psychology, 9(1), 25-82. http://www.univie.ac.at/constructivism/papers/maturana/88reality.html

Maturana, H.R. \& Poerksen, B. (2004). Varieties of objectivity. Cybernetics and Human Knowing, 11(4), 63-71.

Maturana, H.R., \& Varela, F.J. (1992). The tree of knowledge: The biological roots of human understanding (rev. edition). Boston: Shambhala.

Merleau-Ponty, M. (1962). Phenomenology of perception. London, UK: Routledge and Kegan Paul.

Phillips, D. C. (1995). The Good, the Bad, and the Ugly: The many faces of constructivism. Educational Researcher, 24(7), 5-12.

Proulx, J. (2006). Constructivism: A re-equilibration and clarification of the concepts, and some potential implications for teaching and pedagogy. Radical Pedagogy, 8(1). http://radicalpedagogy.icaap.org

Riegler, A. (2005). Editorial. The constructivist challenge. Constructivist Foundations, 1(1), 1-8.

Science et vie. (2005). Une incroyable association insecte-plante a été repérée. June 2005: 18-19.

Tomm, K. (1989). The view of cognition of H. Maturana. An occasional paper and communication given at the University of Alberta (Edmonton, Canada). January 20th, 1989.

Vacher, L-M. (1998). La passion du réel: La philosophie devant les sciences. Montreal: Éditions Liber.

Varela, F.J. (1984). Living ways of sense-making: A middle path for neuroscience. In P. Livingston (Ed.). Disorder and order: Proceedings of the Stanford international symposium (Sept. 14-16, 1981) (pp. 208-224). Saratoga, California: Anma Libri.

Varela, F.J. (1987). Laying down a path in walking. In W.I. Thompson (Ed.). Gaia: A way of knowing. Political implications of the new biology (pp. 48-64). New York: Lindisfarne Press.

Varela, F.J. (1996). Invitation aux sciences cognitives. Paris: Éditions du Seuil. 
Varela, F.J. (1999). Ethical know-how: Action, wisdom, and cognition. Stanford, CA: Stanford University Press.

Varela, F.J., Thompson, E. \& Rosch, E. (1991). The embodied mind: Cognitive science and human experience. Cambridge, MA: MIT Press.

\begin{abstract}
About the Author
Jérôme Proulx, Ph.D., is Assistant Professor at the Faculty of Education at the University of Ottawa, Canada. His research is situated in mathematics teacher education, precisely the study of teachers' knowledge and learning. jerome.proulx@uottawa.ca

(C) Copyright 2008. The author, JÉRÔME PROULX, assigns to the University of Alberta and other educational and non-profit institutions a non-exclusive license to use this document for personal use and in courses of instruction provided that the article is used in full and this copyright statement is reproduced. The author also grants a non-exclusive license to the University of Alberta to publish this document in full on the World Wide Web, and for the document to be published on mirrors on the World Wide Web. Any other usage is prohibited without the express permission of the authors.
\end{abstract}

